\title{
CARDIOVASCULAR SYSTEM PARAMETERS IN PARTICIPANTS OF ARCTIC EXPEDITIONS
}

\author{
NATALIYA B. PANKOVA, IRINA B. ALCHINOVA, ANTON B. CHEREPOV, ELENA N. YAKOVENKO, \\ and MIKHAIL Y. KARGANOV
}

Institute of General Pathology and Pathophysiology, Moscow, Russia

Laboratory of Physical, Chemical and Ecological Pathophysiology

\begin{abstract}
Objectives: A method of continuous heart rate (HR) and blood pressure (BP) recording was used for the evaluation of the cardiovascular system parameters in participants of short-term ( $<1$ month) high-latitude expeditions, in comparison with the parameters of residents of Central Russia and the Arctic region. Material and Methods: A dynamic examination of participants of Arctic expeditions (30 men, residents of middle-latitude regions, aged 46.7 \pm 1.7 years), workers permanently living in Central Russia (the Moscow region, 44 men, aged $46.7 \pm 1.0$ years) and residents of the North (the Murmansk region, 35 men, aged $46.6 \pm 1.3$ years) was performed. The authors used a spiroartheriocardiorythmograph allowing the parallel recording of HR, BP, spectral characteristics of HR variability (HRV) and the variability of systolic BP (sBP) and diastolic BP (dBP), cardiac performance parameters, and spontaneous baroreflex sensitivity (BRS). The parameters were recorded at rest, in a sitting position, over 2 min. Results: The basic clinical parameters (HR, BP and cardiac performance) did not differ in the workers living in different climatic zones. However, the residents of the North demonstrated a lower total power (TP) of the dBP variability spectrum and a lower relative power of the high-frequency (HF) range in both the sBP and $\mathrm{dBP}$ variability spectra. The participants of expeditions to the North had a lower TP of the HRV spectrum (in comparison with both control groups) that did not change during the expeditions; BRS was reduced, while the TP of the sBP spectrum was increased in comparison with the corresponding parameters obtained from the residents of circumpolar regions, and decreased during the expedition in parallel with a decrease in the sBP values. The TP of both the sBP and dBP variability spectra, as well as the power of the HF range in these spectra, were similar in the participants of expeditions to those obtained from the residents of Central Russia, and they considerably surpassed the corresponding parameters in the northerners surveyed. Conclusions: The revealed peculiarities of the cardiovascular system in the participants of high-latitude expeditions can be considered as correlates of positive, and adequate in terms of the physiological value, adaptive shifts in the autonomous regulation of the cardiovascular system. Int J Occup Med Environ Health. 2020;33(6):819-28
\end{abstract}

Key words:

adaptation, heart rate variability, cardiovascular system, climate, blood pressure variability, baroreflex sensitivity

\section{INTRODUCTION}

Cold exposure, e.g., under climatic conditions of the North, has a significant impact on human health; it modifies clinical parameters in healthy people [1] and constitutes a risk factor for the development of various pathologies [2]. This is especially true for residents of temperate climatic zones moving to the North for various reasons: they adapt to cold by any of the possible mechanisms suitable for particular individuals [3,4].
It is known that northern climatic conditions (low temperatures in combination with winds and low insolation) provoke more frequent and more severe cardiovascular disorders in non-indigenous populations, for instance, in rotational workers [5]. Thus, the development of arterial hypertension in migrants, in contrast to the indigenous population, is accompanied by an increase in daily variability of blood pressure (BP) and manifestations of desynchronosis [6]. At the same time, clinical studies

Received: March 17, 2020. Accepted: July 13, 2020

Corresponding author: Nataliya B. Pankova, Institute of General Pathology and Pathophysiology, Laboratory of Physical, Chemical and Ecological Pathophysiology,

Baltiyskaya 8, 125315 Moscow, Russia (e-mail: nbpankova@gmail.com). 
of the same nosological forms (arterial hypertension, atherosclerosis) have revealed compensatory shifts in lipid metabolism in the indigenous population [7].

However, due to a recent development of transportation, the North is now accessible not only for work, scientific research, or extreme sports events, but also for tourism. In light of the above it seems interesting to determine the type (adaptive or destructive) and magnitude of the bodily response in people from temperate latitudes visiting the North for a short time.

Standard methods of clinical observations have revealed changes in the daily variability of the cardiovascular system parameters in participants of long-term expeditions to cold regions [8]. At the same time, methods of evaluation of heart rate (HR) variability (HRV) are very informative [1,7]. The detected changes in the spectral parameters of HRV are interpreted as correlates of changes in the autonomic regulation of HR. In this context, different variants of continuous BP recording based on Jan Peñáz's photoplethysmographic method [9], with a subsequent analysis of variability, seem to be promising. The most popular is the Finometer instrument system that allows accurate BP measurements with an "adjustment" to the results of auscultatory measurements on the other upper arm. This system is very useful in clinical practice [10] but, due to its technical characteristics, it cannot be used in expeditions. Similar technical approaches (with the same disadvantages) are implemented in the Task Force Monitor instrument complex that is also used in clinical practice [11,12]. A portable spiroarteriocardiorhythmograph used in sports medicine [13] is more suitable for infield studies, because a spectral analysis of BP variability forms an integral part of applied software.

The authors' aim was to detect the possible changes in the cardiovascular system parameters (including HRV and $\mathrm{BP}$ variability) assessed by spiroarteriocardiorhythmography in the participants of Arctic expeditions, in comparison with the corresponding indicators obtained from residents of Central Russia and the Arctic region.

\section{MATERIAL AND METHODS \\ Participants}

The authors analyzed the cardiovascular system parameters in workers engaged in various industries and permanently living in a region with moderate climate (Moscow and the Moscow region: $56^{\circ} \mathrm{N}, 38^{\circ} \mathrm{E}$ ) or in the North (the Murmansk region: $\left.69^{\circ} \mathrm{N}, 33^{\circ} \mathrm{E}\right)$. High-latitude expeditions to Franz Josef Land $\left(81^{\circ} \mathrm{N}, 55^{\circ} \mathrm{E}\right)$ started from Murmansk; the participants were individuals permanently living in temperate climate regions. Detailed characteristics of the groups are presented in Table 1.

The expedition groups (Ex_start and Ex_finish) included participants of Arctic expeditions conducted in 2011, 2017, and 2019. The participants of the 2011 expedition were transported to their place of work by air. The participants of the 2017 and 2019 expeditions, which were performed within the framework of the project entitled "Open Ocean: Arctic Archipelagos," sailed onboard the Alter Ego yacht. Descriptions of these expeditions are presented in Table 2.

\section{Instruments}

Cardiovascular system parameters were studied using a spiroarteriocardiorhythmograph (INTOKS, St. Peters-

Table 1. Characteristics of the studied groups of workers from Moscow and the Moscow region $\left(56^{\circ} \mathrm{N}, 38^{\circ} \mathrm{E}\right)$, workers from the Murmansk region $\left(69^{\circ} \mathrm{N}, 33^{\circ} \mathrm{E}\right)$, and the participants of highlatitude expeditions to Franz Josef Land, in 2011, 2017 and 2019

\begin{tabular}{lcc}
\hline & \multicolumn{2}{c}{$\begin{array}{c}\text { Participants } \\
(\mathrm{N}=109)\end{array}$} \\
\cline { 2 - 3 } Studied group & $\mathrm{n}$ & $\begin{array}{c}\text { age } \\
\text { [years] } \\
(\mathrm{M} \pm \mathrm{SE})\end{array}$ \\
\hline Moscow & 44 & $46.7 \pm 1.0$ \\
Expedition & 30 & $46.7 \pm 1.7$ \\
North & 35 & $46.6 \pm 1.3$ \\
\hline
\end{tabular}

Moscow - workers engaged in various industries and permanently living in Moscow and the Moscow region; Expedition - participants of high-latitude expeditions to Franz Josef Land which started from Murmansk; North - workers engaged in various industries and permanently living in the Murmansk region. 
Table 2. Characteristics of expeditions in 2011, 2017 and 2019 to Franz Josef Land, and their participants

\begin{tabular}{|c|c|c|c|c|}
\hline \multirow[b]{2}{*}{ Year } & \multirow[b]{2}{*}{ Month } & \multirow{2}{*}{$\begin{array}{l}\text { Duration } \\
\text { [days] }\end{array}$} & \multicolumn{2}{|c|}{$\begin{array}{l}\text { Participants } \\
(\mathrm{N}=30)\end{array}$} \\
\hline & & & $\mathrm{n}$ & $\begin{array}{c}\text { age } \\
\text { [years] } \\
(\mathrm{M} \pm \mathrm{SE})\end{array}$ \\
\hline 2011 & July-August & 26 & 12 & $47.4 \pm 3.3$ \\
\hline 2017 & August-September & 27 & 9 & $45.3 \pm 2.8$ \\
\hline 2019 & June-July & 26 & 9 & $46.1 \pm 3.0$ \\
\hline
\end{tabular}

burg, Russia) allowing the simultaneous continuous registration of an electrocardiogram in standard lead I (with HRV evaluation), digital BP by photoplethysmography with evaluation of the variability of systolic BP (sBP) and diastolic BP (dBP), as well as respiratory parameters using an ultrasonic sensor for air flow registration (with a spirometric mask, optional). A long-term continuous recording of HR and BP indicators, in addition to the maximum, minimum and mean values, allows assessing spectral parameters of their variability (the total power [TP] of the spectrum, and the absolute and relative power of the standard high-frequency [HF], low-frequency [LF] and very-low-frequency [VLF] ranges), the stress index, and calculated indexes (the LF/HF ratio, the alpha index, and the centralization index). In addition, it allows assessing the sensitivity of spontaneous arterial baroreflex (BRS) and parameters of cardiac performance.

\section{Design of the experiment}

Cardiovascular system parameters were recorded in a sitting position over $2 \mathrm{~min}$. In employees of industrial plants, one registration was performed, either in July-August (residents of the Moscow region) or in September-November (residents of the North); the spirometric mask was not used. In the participants of Arctic expeditions, 2 series of registrations were performed, i.e., before leaving Murmansk (the Ex_start group) and before return (the Ex_finish group). Every time, these groups performed
2 registrations: in a calm state and during a functional test involving controlled breathing ( 6 cycles/min).

\section{Ethics}

All the participants in all series of the experiment signed informed consent forms. Compliance with international laws (including the Helsinki Declaration as revised in 2013) and Russian laws, as regards the legal and ethical principles of scientific research with human participation, was confirmed by the decision of the Ethics Committee of the Institute of General Pathology and Pathophysiology, protocol No. 4, 02.09.2019.

\section{Statistics}

Evaluation of normality of the obtained data arrays using the Shapiro-Wilk test showed that only the participants' age, HR, and BP averaged over the entire registration period met the normality criterion $(p>0.05)$. Hence, intergroup comparisons by these parameters were performed using the ordinary one-way ANOVA algorithm, followed by a comparison of the means using the HolmSidak multiple comparison test; data in the tables and figures are presented as $\mathrm{M} \pm \mathrm{SE}$. In other cases, intergroup comparisons were performed using non-parametric tests: the Mann-Whitney $U$ test for paired comparisons and the Kruskal-Wallis test for multiple comparisons followed by Dunn's multiple comparisons test; data in the figures are presented as medians and interquartile ranges. 

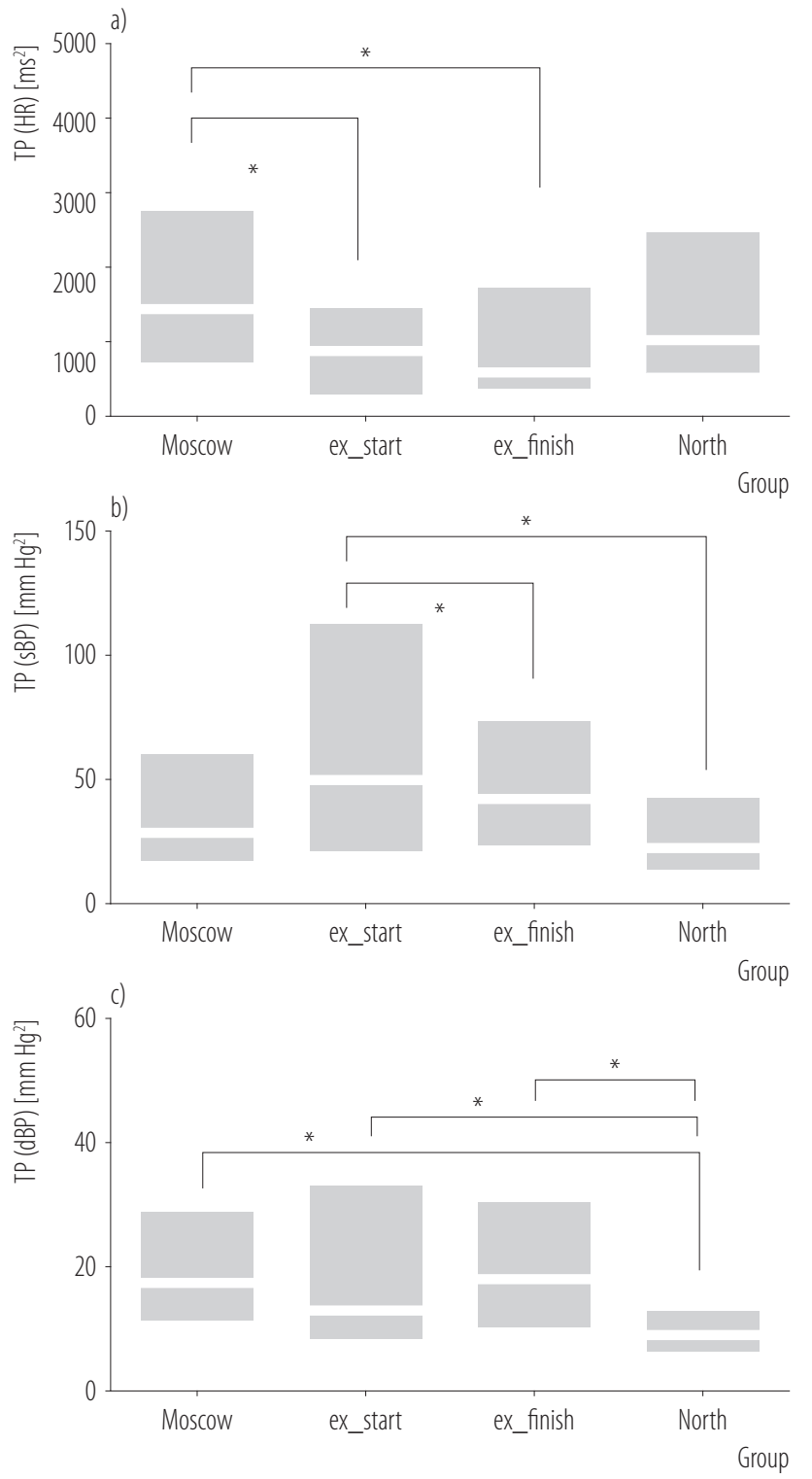

Ex_start - participants of high-latitude expeditions to Franz Josef Land which started from Murmansk, tested at the start; ex_finish participants of high-latitude expeditions to Franz Josef Land which started from Murmansk, tested at the finish.

Other explanations as in Table 1.

* Statistically significant intergroup differences ( $p<0.05$ according to the Mann-Whitney $U$ test).

The data are presented as Me (white line) and IQR (gray rectangles).

Figure 1. Total power (TP) of a) the heart rate (HR) variability spectra, b) systolic blood pressure (sBP), and c) diastolic blood pressure $(\mathrm{dBP})$ in subjects permanently living in a region with moderate climate or in the North, and participants of shortterm high-latitude expeditions in 2011, 2017 and 2019
As the total number of the cardiovascular system parameters that were measured and calculated in each registration was 48, the authors used a discriminant analysis (the forward stepwise algorithm) to identify the most significant parameters.

\section{RESULTS \\ Differences in cardiovascular system parameters between residents of Moscow and the North}

The paired comparison of the cardiovascular system parameters revealed no differences between workers living in different climatic zones in terms of the basic clinical indicators (HR and BP averaged over the registration session, their minimum and maximum values, and cardiac performance). However, some intergroup differences were found in the spectral parameters of HR and BP variability. In particular, a lower TP of the dBP variability spectrum was typical of residents of northern regions (Figure 1c): $\mathrm{Z}=3.963, \mathrm{p}<0.001$. The decrease in the TP of both the HR and sBP variability spectra did not reach the level of statistical significance (Figure 1a and b): $Z=1.371, p=0.170, Z=1.534, p=0.124$, respectively. Moreover, the authors observed a decrease in the relative power of the HF range in both the sBP and $\mathrm{dBP}$ variability spectra in residents of northern regions (Figure 2): $\mathrm{Z}=2.122, \mathrm{p}=0.033, \mathrm{Z}=3.271$, $p=0.001$, respectively. In northerners, this parameter in the HR variability spectrum did not decrease: $\mathrm{Z}=0.631$, $\mathrm{p}=0.527$.

The discriminant analysis confirmed the presence of statistically significant differences in the state of the cardiovascular system in residents of regions with different climatic conditions: Wilks' $\lambda$ : 0.782 approx. $F(7,71)=2.831$, $\mathrm{p}<0.012$. The discrimination model included the following parameters: the relative power of the LF and $\mathrm{HF}$ ranges in the HRV spectrum, the $\mathrm{LF} / \mathrm{HF}$ ratio, the relative power of the $\mathrm{HF}$ range in both the $\mathrm{SBP}$ and $\mathrm{dBP}$ variability spectra, and the maximum sBP value. 


\section{Comparison of data from Arctic expedition participants with the results of residents of Central Russia and northern regions}

Testing performed in a calm state in all 4 groups (residents of different regions and expedition participants in 2 measurements) revealed statistically significant differences in the same indicators as between Moscow and the North. For example, the TP of the HR variability spectrum in expedition participants was lower than in workers from Moscow in both measurements (Figure 1a). The TP of both the sBP and $\mathrm{dBP}$ variability spectra was higher than in residents of northern regions also in both measurements (Figure $1 b$ and $c$ ). The relative power of the HF range in both the sBP and $\mathrm{dBP}$ variability spectra surpassed that obtained from residents of northern regions in both the initial and final registration points (Figure 2). In addition, the authors found that the BRS values in the participants of high-latitude expeditions were lower than in both residents of the Moscow region and northerners (Figure $3 \mathrm{a}$ ). The stress index in expedition participants surpassed the values observed in residents of different regions only at the end of the expedition (Figure $3 \mathrm{~b}$ ). The averaged sBP at the end of the expedition also decreased and significantly differed from that in residents of the Moscow region and the North (Figure 3c).

The discriminant analysis confirmed significant differences between the groups: Wilks' $\lambda$ : 0.644 approx. $F(21,370)=2.920$, $\mathrm{p}<0.001$. The discrimination model included the following parameters: the relative power of the $\mathrm{HF}$ range and the $\mathrm{LF} / \mathrm{HF}$ ratio in the $\mathrm{HRV}$ spectrum, the relative power of the $\mathrm{LF}$ and $\mathrm{HF}$ ranges of the $\mathrm{dBP}$ variability spectrum, and the maximum and mean sBP and BRS. Importantly, some differences were found between residents of Moscow and northern regions, and between both expedition groups and residents of regions with different climate conditions, but not between the start and end points of the expeditions (Table 3 ).

It should be noted that no differences were revealed between the groups in terms of $\mathrm{HR}, \mathrm{dBP}$, and cardiac performance parameters.
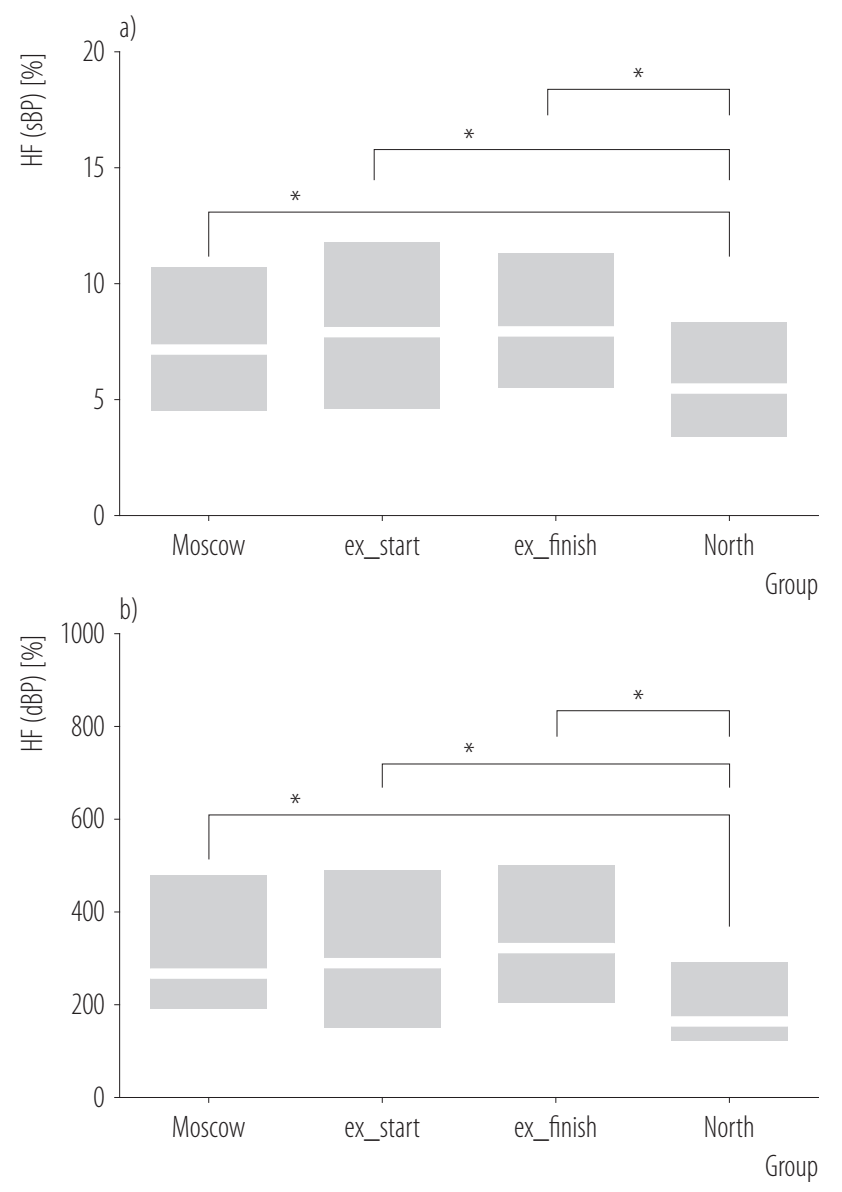

Explanations as in Table 1 and Figure 1.

Figure 2. Relative power of the high-frequency (HF) range of a) systolic blood pressure (sBP) and b) diastolic blood pressure $(\mathrm{dBP})$ variability spectra in subjects permanently living in a region with moderate climate or in the North, and participants of short-term high-latitude expeditions in 2011, 2017 and 2019

\section{Analysis of the results of Arctic expeditions}

The analysis of the dynamics of the cardiovascular system parameters in different expeditions showed that only the decrease in the mean and maximum sBP values was reproduced in all 3 expeditions. Additionally, measurements in a calm state during the 2011 expedition revealed a decrease in the TP of the HR variability spectrum and the stress index; during the 2017 expedition, an increase in the LF/HF ratio was found, and during the 2019 expedition, an increase in the TP of sBP variability spectrum was 

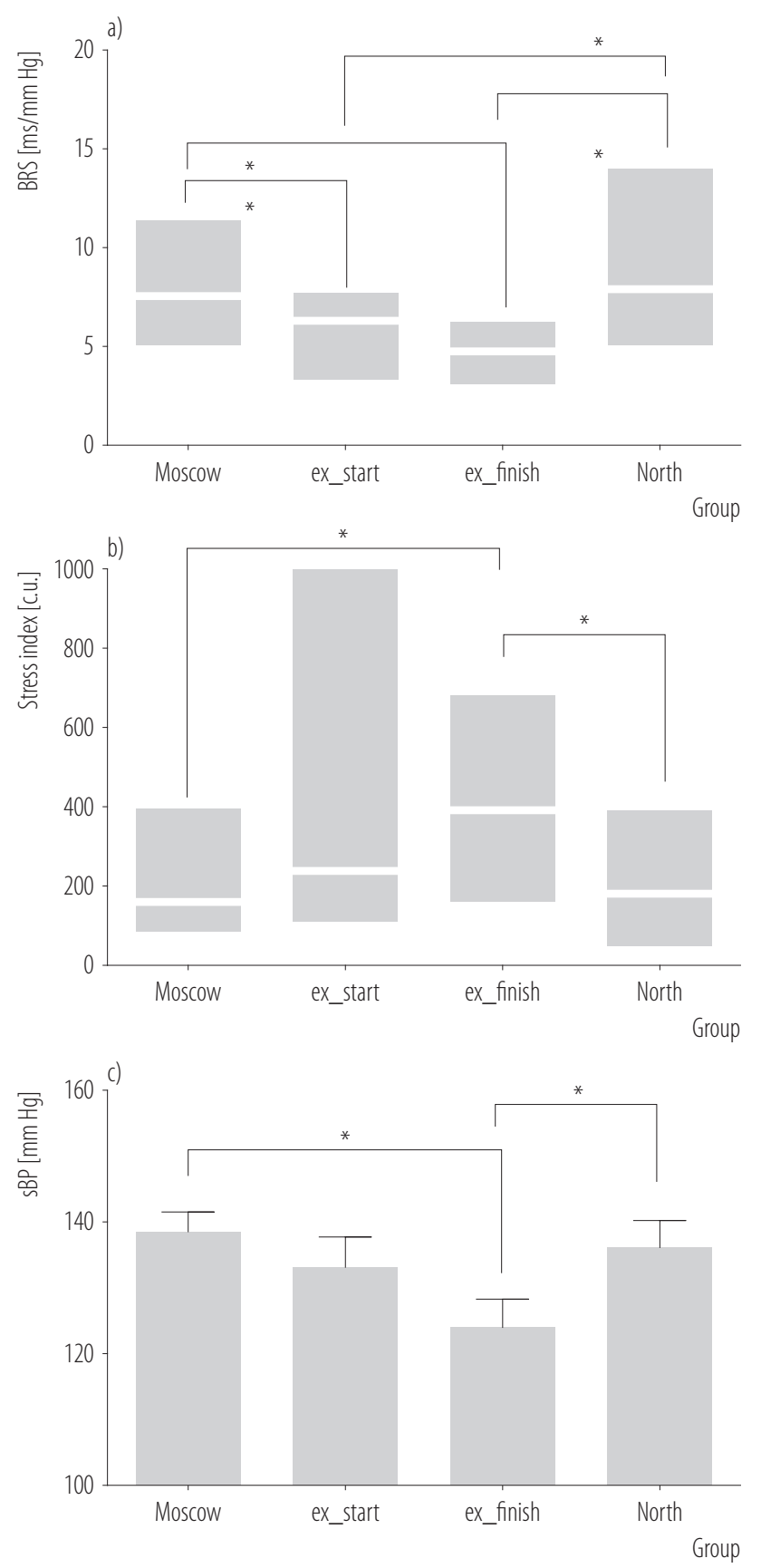

Explanations as in Table 1 and Figure 1.

The data in a) and b) are presented as Me (white line) and IQR (gray rectangles), in c) as the mean and $\mathrm{M} \pm \mathrm{SEM}$.

Figure 3. Sensitivity of the a) spontaneous arterial baroreflex (BRS), b) stress index, and c) systolic blood pressure (sBP) averaged over 2-min registration in subjects permanently living in a region with moderate climate or in the North, and in participants of short-term high-latitude expeditions in 2011, 2017 and 2019 detected. Registration under the conditions of controlled breathing (6 cycles/min; the functional test) revealed an increase in the relative power of the LF range of the HR spectrum during the 2011 expedition and an increase in the relative power of the HF range of the sBP spectrum during the 2019 expedition.

Therefore, the authors used a discriminant analysis to reveal differences in the state of the cardiovascular system of the participants of different expeditions. Significant differences in the functional state of the cardiovascular system were revealed both at the start (Wilks' $\lambda 0.285$ approx. $F(12,44)=3.190, p=0.002$ ) and at the end (Wilks' $\lambda 0.392$ approx. $\mathrm{F}(10,46)=2.740, \mathrm{p}=0.009)$ of different expeditions. Moreover, some differences were found in the dynamics of the analyzed parameters during the expeditions, both in a calm state (Wilks' $\lambda 0.370$ approx. $F(10,46)=$ 2.962, $\mathrm{p}=0.005)$ and under the conditions of controlled breathing (Wilks' $\lambda 0.084$ approx. $F(22,30)=3.338, \mathrm{p}=$ $0.001)$. Some differences at the start and end points were found in the participants of the 2011 and 2019 expeditions ( $p=0.002, p=0.001$, respectively). The dynamics of the parameters recorded in a calm state during the 2019 expedition differed from the results of the 2011 expedition $(p=0.017)$ and the 2017 expedition $(p=0.016)$. The dynamics of the parameters recorded under the conditions of controlled breathing during the 2017 expedition differed from the results obtained during the 2011 expedition $(p<0.001)$ and the 2019 expedition $(p=0.004)$.

\section{DISCUSSION}

The homogeneity of the groups involved in this study is noteworthy. The authors analyzed the cardiovascular system parameters in men of similar age, which allowed them to minimize the influence of gender and age factors $[14,15]$. The time frames in all groups were also close, which minimized the seasonal impact [16].

Under these conditions, it can be assumed that the main differences in the functional capacities of the cardiovascu- 
Table 3. Statistical significance of the differences between individual groups based on the results of the discriminant analysis

\begin{tabular}{lcccc}
\hline \multirow{2}{*}{ Group } & \multicolumn{3}{c}{$\mathrm{p}$} \\
\cline { 2 - 5 } & Moscow & Ex_start & Ex_finish & North \\
\hline Moscow & - & $\mathbf{0 . 0 3 8}$ & $\mathbf{0 . 0 0 1}$ & $\mathbf{0 . 0 0 6}$ \\
Ex_start & $\mathbf{0 . 0 3 8}$ & - & 0.557 & $\mathbf{0 . 0 0 2}$ \\
Ex_finish & $\mathbf{0 . 0 0 1}$ & 0.557 & - & $<\mathbf{0 . 0 0 1}$ \\
North & $\mathbf{0 . 0 0 6}$ & $\mathbf{0 . 0 0 2}$ & $<\mathbf{0 . 0 0 1}$ & - \\
\hline
\end{tabular}

Explanations as in Table 1 and Figure 1.

Bolded are significant differences.

lar system in the participants of Arctic expeditions, compared to representatives of indigenous populations of different regions, do not involve standard clinical indicators (HR, BP and cardiac performance), but only the phenomena visualized by the spectral analysis of variability. In this case, these were the total spectral power and the power of the HF ranges in different spectra. This raises the question about the physiological meaning of the estimated parameters.

Many years ago, European and American cardiology societies developed clinical recommendations for the interpretation of HRV spectral parameters. It was accepted that the total spectral power reflected the overall level of autonomic activity, the HF range reflected vagal (synchronized with breathing) impacts, and the LF range reflected baroreflex and sympathetic impacts [14]. The VLF range reflected various endocrine, metabolic, and psychogenic impacts on $\mathrm{HR}$, but its correct assessment required recording duration of $>5 \mathrm{~min}$. As it conflicted with the design of this experiment, this parameter was not considered.

Blood pressure variability is more difficult to analyze. In most published reports, BP variability means changes in the results of single measurements of BP (often using the auscultatory method) over long periods (a month, a week, a day, or during a medical appointment) [17,18]. The analysis of BP variability in the beet-to-beet mode requires a continuous BP recording $[9,11,12,19,20]$, and is, therefore, less common. This is probably why the physi- ological meaning of the spectral parameters of BP variability is substantiated in only few reports and exclusively for sBP [21]. The LF range was proven to reflect the sympathetic and myogenic modulation of the vascular tone. The HF range associated with respiration can also reflect the activity of endothelial nitric oxide (NO), but this component can be isolated only in tests involving controlled breathing. Diastolic BP variability is more difficult to interpret. Clinicians recognize the predictive importance of both $\mathrm{SBP}$ and $\mathrm{dBP}$ [22], and they assign specific physiological role to each of these components. There is evidence that $\mathrm{dBP}$ reflects, to a greater extent, the resistance of the arterial wall and represents a "stable component" of the arterial sphygmogram [22], whereas sBP is more closely related to pulse BP variations and is considered a "dynamic component" of the arterial sphygmogram. The final sBP value is created by various mechanisms, including left ventricular ejection and reflected wave [23].

In this case, the differences between residents of Central Russia and northern regions were revealed only in the total level of the autonomic regulation of the vascular tone - this parameter was lower in northerners. A lower relative power of the HF range can be a result of a reduced synthesis of endothelial vasodilator NO, but this assumption needs direct biochemical verification.

The participants of Arctic expeditions living in middle-latitude regions were characterized by a lower TP of the HRV spectrum, in comparison with employees of industrial en- 
terprises also living in Central Russia. Changes in the autonomic HR regulation can be determined by lower BRS values and more pronounced emotional stress, which was reflected in the high stress index, especially at the end of the expedition.

The TP of both the sBP and dBP variability spectra, as well as the power of the HF range in these spectra, were close to the corresponding values obtained from workers from Central Russia and considerably surpassed the corresponding parameters in northerners. These results suggest a similar level of the autonomic regulation of the vascular bed in residents of Central Russia irrespective of the type of their occupational activity. However, the decrease in the TP of the SBP variability spectrum ("normalization") and the absolute sBP values observed during the expedition can be interpreted as positive and adequate in the physiological value adaptive changes in the level of the sympathetic regulation of the vascular bed.

The dynamics of the cardiovascular system parameters in the participants of different expeditions deserves special attention. The discriminant analysis showed that, in a calm state, the differences between the parameters and their dynamics in the participants of different expeditions reached the level of statistical significance only for the maximum sBP value, and this parameter changed significantly during all the expeditions. Hence, the differences between the participants of different expeditions could involve the parameters characterizing the autonomic regulation of the vascular tone. This was indirectly proven by the results of the functional test involving controlled breathing.

According to current views, registration at rest is insufficient for the correct assessment of the autonomic regulation and, therefore, various functional tests are required [24]. The authors used the test involving controlled breathing at a rate of 6 cycles/min, because this is the optimal way for the correct evaluation of BRS [25,26] using the parameters of $\mathrm{HR}$ and $\mathrm{SBP}$ variability spectra (the alpha index). However, this instrument allows direct measurements of BRS at the moments of HR and BP coher- ence by averaging the measured values during registration (in this case, over 12 respiratory cycles).

The discriminant analysis of the results of the functional tests showed that, under these conditions, not only the sBP value, but also the $\mathrm{HR}, \mathrm{sBP}$ and $\mathrm{dBP}$ variability parameters, become significant. Different dynamics of these indicators during the expedition explains the differences in the final parameters between the participants of different expeditions. Adaptation to the climatic conditions of the North, including short-term Arctic expeditions, is a special case of human adaptation to changing environmental conditions. Moreover, environmental conditions are changing due to both climate changes and human expansion into regions with climatically unfavorable conditions (extremely cold, hot, arid, humid, etc.).

Climate monitoring has demonstrated an appreciable warming of the planet surface in recent decades. However, humankind seems to be ready for this challenge. Thus, an epidemiological analysis of the structure of mortality in 305 locations within 10 countries (1985-2012) showed that population's susceptibility to heat and heat waves has steadily decreased in recent years [27], though statistics demonstrate increased morbidity and mortality during prolonged heat waves, as was observed in Moscow in 2010 [28]. The weakening of heat-related adaptive changes can be a result of public health strategies for mitigating the effects of climate changes. However, no positive epidemiological changes were found in relation to cold waves [27], which prompts studies of the human adaptation strategy to cold. At the same time, in the context of the expanding area of human presence, it should be noted that the range of cold temperatures acceptable for adaptation is significantly wider than the range of heat temperatures, due to physical and chemical properties of proteins in the human body. Importantly, the processes of adaptation to both cold and heat are accompanied by changes in the cardiovascular system [1-3,29] and in its autonomic regulation, which can be registered in the analysis of HR and BP variability [30]. 


\section{CONCLUSIONS}

Thus, the participants of short-term expeditions to the North differ from residents of Central Russia and polar regions by the spectral characteristics of HRV and BP variability, in particular, by a lower TP of the HRV spectrum that did not change during the expeditions, reduced BRS, and a higher TP of the sBP spectrum that decreased during the expedition in parallel with a decrease in $\mathrm{SBP}$ values. These differences can be considered as correlates of positive, and adequate in terms of the physiological value, adaptive changes in the autonomic regulation of the cardiovascular system.

\section{ACKNOWLEDGMENTS}

The authors are grateful to M.V. Gavrilo, Ph.D., the scientific director of the projects entitled "Open Ocean: Arctic Archipelagos" for research coordination: 2017 - the "Two captains" project, and 2019 - the "Barents" project.

\section{REFERENCES}

1. Bortkiewicz A, Gadzicka E, Szymczak W, Szyjkowska A, Koszada-Włodarczyk W, Makowiec-Dąbrowska T. Physiological reaction to work in cold microclimate. Int J Occup Med Environ Health. 2006;19(2):123-31, https://doi.org/10.2478/ v10001-006-0020-y.

2. Hasnulin VI. [Human health and cosmogeohysical North factors]. Ekologiya Cheloveka. 2013;12:3-13. Russian.

3. Castellani JW, Young AJ. Human physiological responses to cold exposure: Acute responses and acclimatization to prolonged exposure Auton Neurosci. 2016;196:63-74, https:/doi. org/10.1016/j.autneu.2016.02.009.

4. Krivoschekov SG, Belisheva NK, Nikolaeva EI, Vergunov EG, Martynova AA, Elnikova OE, et al. [The Concept of Allostasis and Human Adaptation in the North]. Ekologiya Cheloveka. 2016;7:17-25. Russian.

5. Hasnulin VI, Voevoda MI, Hasnulin PV, Artamonova OG. [Modern Approach to Arterial Hypertension in the Circumpolar and Arctic Regions. Literature Review]. Ekologiya Cheloveka. 2016;3:43-51. Russian.
6. Shurkevich N, Vetoshkin A, Gapon L, Gubin D. The pathogenesis of hypertensive heart in extreme North conditions. J Hypertens. 2018;36(e-S1):e56, https://doi.org/10.1097/01. hjh.0000539114.75195.08.

7. Gapon LI, Sereda TV, Leont'eva AV. [Analysis of 24-hour blood pressure profile, heart rate variability and carotid atherosclerosis in hypertensive patients among native and nonnative population living in Yamalo-Nenets autonomous district]. Kardiologiia. 2014;54(8):32-6. Russian.

8. Brat K, Homolka P, Cornélissen G, Merta Z, Homolka M, Rihacek I, et al. Chronobiological changes in arterial blood pressure in participants of the 5th and 6th Czech Antarctic Scientific Expeditions. Neuro Endocrinol Lett. 2015;36(1):80-3.

9. Nováková Z. From the first spectral analysis of blood pressure variability in the world to the present time: contribution of the Department of Physiology of the Faculty of Medicine, Masaryk University, Brno. Physiol Res. 2013;62(4):341-50.

10. Francica Grilletti JV, Scapini KB, Bernardes N, Spadari J, Bigongiar A, de Andrade F, et al. Impaired Baroreflex Sensitivity and Increased Systolic Blood Pressure Variability in Chronic Post-Ischemic Stroke. Clinics. (Sao Paulo) 2018;73: e2532018, https://doi.org/10.6061/clinics/2018/e253.

11. Tian G, Xiong L, Leung H, Soo Y, Leung T, Ka-Sing Wong L. Beat-to-beat Blood Pressure Variability and Heart Rate Variability in Relation to Autonomic Dysregulation in Patients With Acute Mild-Moderate Ischemic Stroke. J Clin Neurosci. 2019;64:187-93, https://doi.org/10.1016/j.jocn.2019.03.003.

12. Zawadka-Kunikowska M, Słomiński K, Słomko J, TafilKlawe M, Klawe JJ, Sokołowski L, et al. Comprehensive Non-Invasive Cardiac and Autonomic Assessment in Acute Ischemic Stroke Patients: A Pilot Study. Minerva Cardioangiol. 2018;66(4):376-85, https://doi.org/10.23736/S00264725.18.04511-5.

13. Guzii O, Romanchuk A, Mahlovany A, Trach V. Polyfunctional express-evaluation criteria of the sportsman organism state. J Phys Edu Sport. 2019;19(4):2352-8, https://doi. org/10.7752/jpes.2019.04356. 
14. Bernardi L, Spallone V, Stevens M, Hilsted J, Frontoni S, Pop-Busui R, et al. Methods of investigation for cardiac autonomic dysfunction in human research studies. Diabetes Metab Res Rev. 2011;27(7):654-64, https://doi.org/10.1002/ dmrr.1224.

15. Shaffer F, Ginsberg JP. An Overview of Heart Rate Variability Metrics and Norms. Front Public Health. 2017;5:258, https://doi.org/10.3389/fpubh.2017.00258.

16. Markov A, Solonin I, Bojko E. Heart rate variability in workers of various professions in contrasting seasons of the year. Int J Occup Med Environ Health. 2016;29(5):793-800, https://doi.org/10.13075/ijomeh.1896.00276.

17. Stevens SL, Wood S, Koshiaris C, Law K, Glasziou P, Stevens RJ, et al. Blood Pressure Variability and Cardiovascular Disease: Systematic Review and Meta-Analysis. BMJ. 2016;354:i4098, https://doi.org/10.1136/bmj.i4098.

18. Kikuya M, Asayama K, Ohkubo T. Blood pressure variability and arterial stiffness parameters derived from ambulatory blood pressure monitoring. Kardiol Pol. 2019;77(5):509-14. https://doi.org/10.33963/KP.14845.

19. Michel-Chávez A, Estañol B, Gien-López JA, Robles-Cabrera A, Huitrado-Duarte ME, Moreno-Morales R, et al. [Heart rate and systolic blood pressure variability on recently diagnosed diabetics]. Arq Bras Cardiol. 2015;105(3):276-84, https://doi.org/10.5935/abc.20150073. Portuguese.

20. Barendregt PJ, Tulen JHM, van den Meiracker AH, Markusse HM. Spectral analysis of heart rate and blood pressure variability in primary Sjögren's syndrome. Ann Rheum Dis. 2002;61:232-6, https://doi.org/10.1136/ard.61.3.232.

21. Stauss HM. Identification of Blood Pressure Control Mechanisms by Power Spectral Analysis. Clin Exp Pharmacol Physiol. 2007;34(4):362-8, https://doi.org/10.1111/j.1440-1681.2007. 04588.x.

22. Flint AC, Conell C, Ren X, Banki NM, Chan SL, Rao VA, et al. Effect of Systolic and Diastolic Blood Pressure on
Cardiovascular Outcomes. N Engl J Med. 2019;381(3):24351, https://doi.org/10.1056/NEJMoa1803180.

23. Pede S, Lombardo M. [Cardiovascular Risk Stratification. Systolic, Diastolic or Pulse Pressure?]. Ital Heart J Suppl. 2001;2(4):356-8. Italian.

24. Low PA, Tomalia VA, Park KJ. Autonomic function tests: some clinical applications. J Clin Neurol. 2013;9(1):1-8, https://doi.org/10.3988/jen.2013.9.1.1.

25. Rydlewska A, Ponikowska B, Borodulin-Nadzieja L, Banasiak W, Jankowska EA, Ponikowski P. [Assessment of the functioning of autonomic nervous system in the context of cardiorespiratory reflex control]. Kardiol Pol. 2010;68(8): 951-7. Polish.

26. Pinna GD, Maestri R, La Rovere MT. Assessment of baroreflex sensitivity from spontaneous oscillations of blood pressure and heart rate: proven clinical value? Physiol Meas. 2015;36(4):741-53, https://doi.org/10.1088/0967-3334/ $36 / 4 / 741$.

27. Vicedo-Cabrera AM, Sera F, Guo Y, Chung Y, Arbuthnott K, Tong S, et al. A Multi-Country Analysis on Potential Adaptive Mechanisms to Cold and Heat in a Changing Climate. Environ Int. 2018;111:239-46, https://doi. org/10.1016/j.envint.2017.11.006.

28. Revich BA. [Heat-wave, air quality and mortality in European Russia in summer 2010: preliminary assessment]. Ekologiya Cheloveka. 2011;7:3-9. Russian.

29. Heinonen I, Laukkanen JA. Effects of heat and cold on health, with special reference to Finnish sauna bathing. Am J Physiol Regul Integr Comp Physiol. 2018;314(5):R629-38, https://doi.org/10.1152/ajpregu.00115.2017.

30. Stacey MMJ, Delves SK, Woods DR, Britland SE, Macconnachie L, Allsopp AJ, et al. Heart rate variability and plasma nephrines in the evaluation of heat acclimatisation status. Eur J Appl Physiol. 2018;118(1):165-74, https://doi. org/10.1007/s00421-017-3758-y.

This work is available in Open Access model and licensed under a Creative Commons Attribution-NonCommercial 3.0 Poland License - http://creativecommons.org/ licenses/by-nc/3.0/pl/deed.en. 